\title{
THE SIGNIFICANCE OF ANCHORING BIAS IN ESTIMATING FINANCIAL AND ECONOMIC INDICATORS: AN EXPERIMENTAL STUDY IN INDONESIA SETTING
}

\author{
Tassya Andini \\ Marwan Asri \\ (marwan@mmugm.ac.id) \\ Gadjah Mada University
}

\begin{abstract}
Anchoring, in Behavioral Finance terminology, refers to people's tendency to rely too much on the initial piece of information offered (the "anchor"). Anchoring is widely found in decion making processes, where people make estimates about the likelihood of uncertain events or to predict or recall certain values or outcomes by considering the anchor value and adjusting it upwards or downwards to reach a final estimate. Such adjustments are often insufficient, leaving a cognitive bias in the direction of the initial anchor value (Tversky \& Kahneman, 1974). This experimental study was performed in order to detect the presence of anchoring bias in Indonesian setting. Following Kudryavtsev and Cohen (2010)'s procedure, we randomly devided participants into two groups, namely: "control group" (where participants did not receive any anchor value) and "anchoring group" (where participants received some anchoring values). Participants in both groups were instructed to provide their best estimations or answers to questions regarding financial and economic issues. Anchors and the questions were presented with the same order and were expressed in the same scale. Using students of Master of Management Program Universitas Gadjah Mada as respondents, this research was aimed to see whether the answers provided by participants in the anchoring group were affected by the anchor values. Further, we would like to test whether the degree of anchoring biases among female respondents were higher than the biases among male respondents; whether questions related to older topics created higher anchoring biases than the newer ones; and finally, whether anchoring bias among nonfinance major students were higher than those among finance students. The results show that anchoring biases were identified among all participants. However, we could not identify higher degree of anchoring bias among female participants than those among male participants. Similarly, we did not identify higher biases in answering questions with older topics than the newer ones. Finally, higher degree of anchoring biases were found among non-finance major students than in finance major students, suggesting the type of knowledge might affect the degree of anchoring bias.
\end{abstract}

Keywords: anchoring, anchoring bias, anchoring and adjustment, financial and economic indicator. 


\section{INTRODUCTION}

The presence of some cognitive biases in human's daily life is always interesting to syudy because it affects the quality of decision, estimation, or prediction. One of the possible causes of the bias is the over-reliance on a particular initial piece of information to make subsequent judgments and estimations. In other words, people are not in a quite independent position when they are constructing their estimations. Tversky and Kahneman (1974) mentioned that "in many situations, people estimates by starting from an initial value that is adjusted to yield the final answer". In other words, there is a heuristic procedure of decision making with tendency to estimates about the likelihood of uncertain events, or to predict or recall certain values or outcomes, by considering an initial value and adjusting it upwards or downwards to yield a final estimate. Such initial value is called the anchor. Further, Tversky and Kahneman underlined that such adjustments are often insufficient, leaving judgments biased in the direction of the anchor, which is called the anchoring bias.

Quoting Chapman and Johnson (1994), Gilovich et al. (2002) explained some characteristics of anchoring bias. Anchoring bias might exist when participants pay adequate attention to the anchor value. Anchoring bias might also occur if there is an anchor-target compatibility which comes from the similarity between scale and dimension of the anchor value and the estimation. Interestingly, they identified that anchoring bias might exist even though people notice that the anchor value is so extreme and might affect their judgment. Further more, they claimed that even if there are incentives for accurate judgment, there is still a room for anchoring heuristic behavior to take place.

There are quite large numbers of studies have been conducted in this area, and most of them confirmed the existence of anchoring bias in various fields of knowledge, environment, and situation. Cen et al. (2010) conducted a study to investigate the role of anchoring bias in Amercan Equity market using NYSE, Amex and Nasdaq-listed common stocks as their basic sample. They found that anchoring bias played a significant role in financial market significance. More specifically, they concluded that analysts make optimistic forecasts when a firm's forecast earnings per share (FEPS) is lower than the industry median, and vice versa. Further, they underlined that firms with FEPS greater (lower) than the industry median experience abnormally high (low) future stock returns, particularly around subsequent earnings announcement dates. Cen et al. also mentioned that "split firms experience greater positive forecast revisions, larger forecast errors, and larger negative earnings surprises after a stock split compared to which did not split their stocks, especially for firms with a low FEPS relative to the industry median." (Cen et al, 2010).

Many researchers focused their attention to the presence in other areas. Williams (2010), for instance, identified the anchoring bias in military decision making process. He mentioned that, historically, anchoring bias has had harmful effects on military operations. He claimed that "the average number of U.S. troops in Iraq from May 2003 to April 2007 was 138,000. Mounting evidence during this time exposed this initial estimate as insufficient, yet decision makers were anchored on this number over the course of this four-year period. They did not upwardly adjust the number until Iraq was on the verge of a civil war between Sunnis and Shiahs. 
The anchoring phenomenon kept the value closer to the initial value than it should have been."

Kudryartsev and Cohen (2010) conducted a study which is concentrated in anchoring bias in economic and financial issues. They analyzed the role of the anchoring (bias) in perceiving economic and financial information and, in particular, the effect of pre-existing knowledge on the degree of the bias in Israel. Participants of their study were MBA students, assumed to be familiar with financial and economic indicators. Participants were separated into two groups: Anchoring group (where participants were given an anchor value and asked to provide the best estimations/answers towards questions regarding financial and economic indicators) and Control group (where participants are also asked to provide the best estimations/answers towards questions regarding financial and economic indicator without any anchor value). Kudryavtsev and Cohen conclude that the answers of participants in the anchoring group tend to be biased toward the direction of anchor value. They also found a higher degree of anchoring bias among female participants, among older participants, and in "difficult" questions.

Kudryavtsev and Cohen also performed another study in 2011 . They focused their study in comparing the anchoring and hindsight biases among male and female respondents. They identified higher mean and median of anchoring biases among female participants than in male participants. Kudryavtsev and Cohen explained this difference by quoting Feingold (1994), Helgeson (1994 and 2003), Fritz \& Helgeson (1998) who claimed that the difference between men and women can be originated from different thinking patterns. Men's thinking patterns are more assertive and are more independent (in actions and in thoughts) than of women's. Further, Kudryavtsev and Cohen also quoted the studies of Cross and Madson (1997), Gabriel and Gardner (1999), also Hyde (2005) about some other differences between men and women. They explained that women tend to develop interdependent relationship or relational self construct reflecting the importance of social relationship, while men tend to develop independent relationship and independent self construct which reflects assertive attitude and dominance. They also mentioned that women tend to share or take knowledge from surroundings and to cooperate or to follow ideas suggested by others, while men tend to take more risks and are more independent. Men also tend to think more globally, while women tend to think more detailed. Women pay more attention to the anchor values, and therefore their estimation closer to the anchor values.

Smith, Windschitl and Bruchmann (2013) conducted a study to explain the effect of knowledge on anchoring bias. They found that people with higher knowledge were less influenced by anchor values than people with lower knowledge. However, anchoring bias does not depend only on the intensity of knowledge but also depend on the type of knowledge itself. Brown and Siegler's (1993) argued that there are two kinds of knowledge: mapping knowledge and metric knowledge. Mapping knowledge is related to how an item as compared to another item, while the metric knowledge is related to statistical or factual of an item (e.g. its value, mean or median). Someone with metric knowledge will be more resistant towards anchoring bias than someone with mapping knowledge (Smith, 2011). 


\section{RESEARCH METHODS AND HYPOTHESIS}

This research follows Kudryavtsev and Cohen's research design and methodology. So, as an initial step, we defined the population from which the samples (participants) to be selected. The population of this research is the students of Master of Management Program Faculty of Economics and Business Universitas Gadjah Mada, Jakarta Campus, Indonesia, under the assumption that the students of this program have sufficient economic and financial knowledge. We selected 166 students as the samples for the study. Following Kudryavtsev and Cohen, we divided them into two groups. The first group is anchoring group, where the participants are provided with some anchor values before answering questions and making some predictions or judgments about some economicfinancial indicators. The second group is the control group, which consists of participants who are not "equipped" with anchor values. There were 86 students randomly apppointed for the anchoring group (46 males and 40 females) and 80 students in the control group (42 males and 38 females).

We provided questionnaires with similar questions for the participants in both groups. The questionnaires used in this study is consistent with questionnaires developed by Kudryavtsev and Cohen (2010), which consisted of 21 questions regarding financial and economic indicators. We translated the questionnaire to Indonesian and made some necessary adjustment in order to match the questions with financial and economic conditions in Indonesia. Consistent with Kudryartsev and Cohen's questionnaires, we divided the questions into two categories: "easy" questions and "difficult" questions. We follow their definition of easy questions as the questions related to more recent or newer topics; and difficult questions as the questions related to older topics.

There are four hypothesis analyzed in this research. The first hypothesis is related to the existence of anchoring bias. More specifically, we predicted that anchoring bias exist in the anchoring group, so their answers were expected to be closer to anchor values than those participants in the control group. The first hypothesis is expressed as follows:

$H_{1}$ : Anchoring bias can be identified among participants in answering questions with respect to financial and economic indicators.

Further, we developed a second hypothesis to deepen our analysis, especially related to the differences between male's and female's anchoring biases. In their research, Kudryavtsev and Cohen (2010) identified different anchoring bias between male and female participants, where female participants showed higher degree of anchoring bias. Nofsinger (2001) explained that men are more confident than women because they assume that they have more knowledge to back their decisions. Smith (2011) also added that someone with more confidence will be less affected by anchoring bias. The hypothesis is then expressed as follow:

$\mathrm{H}_{2}$ : Anchoring bias among female participants is higher than anchoring bias among male participants.

Another concern with respect to anchoring bias is whether the significance of anchoring bias is determined by the "quality" of questions, or more precisely, the degree of question's difficulty. For practical purposes, a question is considered as a "difficult" question if it is related to older topics, and as an "easy" question if it is 
related to newer topics. We assume that informations about older topics are more difficult to recall, and vice-versa, informations about newer topics are easier to recall. In general, researchers agreed that degree of question's difficulty significantly affected the anchoring bias and that anchoring bias is found to be higher when answering "difficult" questions. However, in their research, Brown \& Siegler (as quoted in Smith, 2011), claimed that the difficulties to recall past information (or older/newer topics) did not affect anchoring bias, but instead, they proved that the type of knowledge (either mapping knowledge or metric knowledge) had significant impact to anchoring bias. Therefore, the third hypothesis is presented as follows:

$\mathrm{H}_{3}$ : Anchoring bias in answering difficult questions is higher than anchoring bias in answering easy questions.

Finally, we intend to explore the role of specific knowledge in "producing" anchoring bias. For this purpose we separated the participants into two groups based on their majors: Finance and Non-Finance. We assumed that students majoring in Finance were more familiar with the determinants of economics and financial indicators as compared to the non-finance students. Therefore, when they are exposed to questions related to economic and financial indicators, we predict that their answer would have been more varied than the answers of nonfinance students. In other words, when we provide anchor information to both groups, we predict that non-finance student will be more "anchor oriented", so the anchoring bias degree should have been greater.

$\mathrm{H}_{4}$ : Anchoring bias among participants majoring in Non-finance is higher than anchoring bias among participants majoring in Finance.

The initial step of our analysis following the data collection is measuring the anchoring bias. We applied the following Kudryavtsev and Cohen's (2010) formula to measure the anchoring bias.

$$
A_{n}^{i}=1-\frac{\left\|R A_{n}^{i}-I_{n}\right\|}{D C_{n}}
$$

In equation 1, $A_{n}^{i}$ is anchoring bias measurement for $n^{\text {th }}$ question and $i^{\text {th }}$ participant; $R A i_{n}$ is the actual answer for $n^{\text {th }}$ question by $i^{\text {th }}$ participant in anchoring group; $\ln$ is the anchor value for $n^{\text {th }}$ question; and $D C_{n}$ is the mean deviation from anchor value for $\mathrm{n}^{\text {th }}$ question in control group.

The mean deviation ( $D C_{n}$ ) was calculated using the following formula:

$$
D C_{n}=\frac{\sum_{j=1}^{N C}\left\|R C_{n}^{j}-I_{n}\right\|}{N C}
$$

where $R C_{n}$ is the actual answer for $n^{\text {th }}$ question by $j^{\text {th }}$ participant in control group, and $N C$ is the number of participants in control group.

Following Kudryavtsev and Cohen's, we calculated the mean anchoring bias for each question (using equation 3 ) and for each participant in anchoring group (using equation 4).

$$
\begin{aligned}
A Q_{n} & =\frac{\sum_{i=1}^{N A} A_{i}^{n}}{N A} \\
A P^{i} & =\frac{\sum_{n=1}^{N Q} A_{i}^{n}}{N Q}
\end{aligned}
$$


$A Q_{n}$ is the mean of anchoring bias for $n^{\text {th }}$ question; NA is the number of participants in anchoring group; $A P i$ is the personal anchoring measure for each participant; and NQ is the number of questions in the questionnaire.

In order to compare the anchoring bias for easy and difficult questions, we folowed Kudryartsev and Cohen's by applying their formulas shown in equation 5 and 6 respectively:

$$
\begin{aligned}
\boldsymbol{A P E}^{i}=\frac{\left.\sum_{i=1}^{N E} A_{i}\right|_{\text {easy }}}{N E} \\
\boldsymbol{A P D}^{i}=\frac{\left.\sum_{i=1}^{N D} A_{i}\right|_{\text {difficult }}}{N D}
\end{aligned}
$$

where $A P E^{i}$ is the mean personal anchoring measure for easy questions for $j^{\text {th }}$ participant; APDi is the mean personal anchoring measure for difficult questions for $i^{\text {th }}$ participant; $\sum_{i=1}^{N E} A_{i}$ leasy is the total of $i^{\text {th }}$ participant anchoring measures for easy questions; $\sum_{i=1}^{N D} A_{i} \mid$ difficult is the total of $i^{\text {th }}$ participant anchoring measures for difficult questions; and NE and ND are the number of easy and difficult questions, respectively. We set up 11 easy questions and 10 difficult ones for each respondent, consistent with Kudryavtsev and Cohen 's questionnaire (2010).

After calculating anchoring measures, we performed statistical tests. In order to test the first hypothesis, we applied one sample t-test in order to identify whether the mean of anchoring bias for $n^{\text {th }}$ question is significantly positive. In other words, if the anchoring measure's mean is significantly greater than zero $\left(A Q_{n}>0\right)$ we cannot reject accept the hypothesis. For Hypothesis 2, 3, and 4, we applied independent sample t-test to compare the gap between two means from two independent samples with the assumption of normally distributed data. We also performed a Mann-Whitney test to compare the gap between two median from two independent samples.

\section{RESULTS AND DISCUSSIONS}

\section{Descriptive Statistics}

The descriptive statistics of the sample are presented in Tables 1 and 2. Table 1 contains summary statistics for the distribution of participants according to their gender in each group and in total respondent. In both groups the number of male participants are slightly higher than that of female participants. In total, $53 \%$ or 88 of participants are males and $47 \%$ or 78 of participants are females.

\section{Table 1: Distribution of Research Participants}

\section{(by Gender)}

\begin{tabular}{|c|c|c|c|c|c|c|}
\hline \multirow{2}{*}{ Gender } & \multicolumn{2}{|c|}{ Anchoring Group } & \multicolumn{2}{c|}{ Control Group } & \multicolumn{2}{c|}{ Total Participants } \\
\cline { 2 - 7 } & Frequency & $\begin{array}{c}\text { Percent } \\
(\%)\end{array}$ & Frequency & $\begin{array}{c}\text { Percent } \\
(\%)\end{array}$ & Frequency & $\begin{array}{c}\text { Percent } \\
(\%)\end{array}$ \\
\hline Male & 46 & $53.5 \%$ & 42 & $52.5 \%$ & 88 & $53 \%$ \\
\hline Female & 40 & $46.5 \%$ & 38 & $47.5 \%$ & 78 & $47 \%$ \\
\hline Total & 86 & $100 \%$ & 80 & $100 \%$ & 186 & $100 \%$ \\
\hline
\end{tabular}


Distribution of research participants according to their majors is presented in Table 2. As we can see, the number of non-finance participants are significantly higher than that of finance major participants. However, we intentionally presented this composition in order to show the real composition of majors or concentration area selected by the entire students of the program (population).

Table 2: Distribution of Research Participants (by Major of Study)

\begin{tabular}{|c|c|c|c|c|c|c|}
\hline \multirow{2}{*}{$\begin{array}{c}\text { Participant's } \\
\text { Majors }\end{array}$} & \multicolumn{2}{|c|}{ Anchoring Group } & \multicolumn{2}{c|}{ Control Group } & \multicolumn{2}{c|}{ Total Participants } \\
\cline { 2 - 7 } & Frequency & $\begin{array}{c}\text { Percent } \\
(\%)\end{array}$ & Frequency & $\begin{array}{c}\text { Percent } \\
(\%)\end{array}$ & $\begin{array}{c}\text { Frequency } \\
\text { Percent } \\
(\%)\end{array}$ \\
\hline NonFinance & 74 & 86.1 & 62 & 77.5 & 136 & 81.9 \\
\hline Finance & 12 & 13.9 & 18 & 22.5 & 30 & 18.1 \\
\hline Total & 86 & $100 \%$ & 80 & $100 \%$ & 166 & 100 \\
\hline
\end{tabular}

\section{Statistical Results}

\section{Hypothesis 1}

In hypothesis 1, we predicted that anchoring bias occur among participants in answering questions with respect to financial and economic indicators. In other words, we hypothesized that $A Q_{n}>0$. Table 3 shows the mean, median, standard deviation, maximum and minimum values of anchoring bias ( $\left.A^{i} n\right)$ for every question. The last two columns of Table 3 show the t-statistics and the significance of anchoring bias for each question.

Table 3: Anchoring Bias for 21 Questions

\begin{tabular}{|c|c|c|c|c|c|c|c|c|c|}
\hline \multirow{2}{*}{$\begin{array}{l}\text { Question } \\
\text { Number }\end{array}$} & \multicolumn{5}{|c|}{ Anchoring Bias $\left(A_{n}\right)$} & \multirow{2}{*}{$\begin{array}{c}\text { Number } \\
\text { Of } \\
\text { Positive }\end{array}$} & \multirow{2}{*}{$\begin{array}{c}\% \\
\text { Of } \\
\text { Positive }\end{array}$} & \multicolumn{2}{|c|}{$A Q_{n}>0$} \\
\hline & Mean & Median & $\begin{array}{l}\text { Standard } \\
\text { Deviation }\end{array}$ & Max & Min & & & t-stat & Sig \\
\hline 1 & 0.4832 & 0.7182 & 0.4921 & 1.00 & -0.1320 & 54 & 63 & 9.106 & 0.000 \\
\hline 2 & 0.6623 & 0.8399 & 0.4763 & 1.00 & -1.6772 & 80 & 93 & 12.894 & 0.000 \\
\hline 3 & 0.3769 & 0.8540 & 1.5741 & 1.00 & -8.3339 & 78 & 91 & 2.221 & 0.015 \\
\hline 4 & 0.7053 & 0.9849 & 1.1057 & 1.00 & -7.1580 & 82 & 95 & 5.915 & 0.000 \\
\hline 5 & 0.8186 & 0.8817 & 0.2789 & 1.00 & -1.0076 & 84 & 98 & 27.223 & 0.000 \\
\hline 6 & 0.7878 & 0.9431 & 0.5430 & 1.00 & -3.4963 & 84 & 98 & 13.453 & 0.000 \\
\hline 7 & 0.8413 & 0.9358 & 0.3150 & 1.00 & -1.6304 & 85 & 99 & 24.768 & 0.000 \\
\hline 8 & 0.4715 & 0.7439 & 0.5335 & 1.00 & -0.6924 & 63 & 73 & 8.195 & 0.000 \\
\hline 9 & 0.6811 & 0.9446 & 2.0274 & 1.00 & -17.8586 & 85 & 99 & 3.115 & 0.001 \\
\hline 10 & 0.7618 & 0.8575 & 0.5085 & 1.00 & -3.5945 & 85 & 99 & 13.895 & 0.000 \\
\hline 11 & 0.7433 & 0.7899 & 0.2841 & 1.00 & -0.5921 & 83 & 97 & 24.265 & 0.000 \\
\hline 12 & 0.6901 & 0.8801 & 0.3773 & 1.00 & -0.8966 & 78 & 91 & 16.962 & 0.000 \\
\hline 13 & 0.6043 & 0.6049 & 0.3214 & 1.00 & -0.8765 & 83 & 97 & 17.438 & 0.000 \\
\hline 14 & 0.5467 & 0.5796 & 0.3625 & 1.00 & -0.8917 & 79 & 92 & 13.987 & 0.000 \\
\hline 15 & 0.5265 & 0.5612 & 0.5008 & 1.00 & -2.7843 & 77 & 90 & 9.750 & 0.000 \\
\hline 16 & 0.7446 & 0.8744 & 0.2645 & 1.00 & -0.3235 & 84 & 98 & 26.109 & 0.000 \\
\hline 17 & 0.5423 & 0.6872 & 0.5222 & 1.00 & -1.4026 & 70 & 81 & 9.630 & 0.000 \\
\hline 18 & 0.5032 & 0.5171 & 0.3737 & 1.00 & -0.9594 & 80 & 93 & 12.489 & 0.000 \\
\hline 19 & 0.6849 & 0.8642 & 0.4619 & 1.00 & -2.2125 & 78 & 91 & 13.749 & 0.000 \\
\hline 20 & 0.7208 & 0.9338 & 0.5363 & 1.00 & -3.2393 & 82 & 95 & 12.463 & 0.000 \\
\hline 21 & 0.7595 & 0.9134 & 0.4437 & 1.00 & -2.1889 & 81 & 94 & 15.874 & 0.000 \\
\hline
\end{tabular}

The results of calculations and statistical tests strongly indicate the existence of anchoring bias for all questions. All means for 21 questions are significantly positive (anchoring bias for 20 of 21 questions are significant at $1 \%$ level of confidence, and 1 question is signicant at $5 \%$ level). The mean values range between 0.3769 
and 0.8413. Thus, the first hypothesis can not be rejected, indicating the presence of anchoring bias.

\section{Hypothesis 2}

Hypothesis 2 is regarding the anchoring bias differences between male and female. We hypothesized that anchoring bias among female participants is higher than anchoring bias among male participants in answering questions regarding financial and economic indicators in Indonesia. More specifically, we hypothesized that mean (and median) of female personal anchoring measures ( $\mathrm{AP}$ i, female) is greater than mean (and median) of male personal anchoring measures (APi, male). While a mean difference t-test (independent sample) was applied in order to identify the difference of means, the diferences in median were tested by using Wilcoxon/Mann-Whitney test. The results of those tests are summarized and presented in Table 4.

Table 4: Female vs Male Personal Anchoring Measures

\begin{tabular}{|c|c|c|c|c|c|c|c|}
\hline \multirow{2}{*}{ Gender } & \multicolumn{7}{|c|}{ Personal Anchoring Measure (APi) } \\
\hline & Mean & Median & $\begin{array}{c}\text { Std. } \\
\text { Deviation }\end{array}$ & $\operatorname{Max}$ & Min & $\begin{array}{l}\mathrm{Nu} \\
\mathrm{Pos}\end{array}$ & $\begin{array}{l}\text { of } \\
\%)\end{array}$ \\
\hline Total (86) & 0.6571 & 0.6850 & 0.2589 & 0.97 & -0.70 & 83 & $\begin{array}{c}96.5 \\
\% \\
\end{array}$ \\
\hline Male (46) & 0.6368 & 0.6500 & 0.2098 & 0.97 & -0.11 & 45 & $\begin{array}{c}97.8 \\
\% \\
\end{array}$ \\
\hline $\begin{array}{c}\text { Female } \\
\text { (40) }\end{array}$ & 0.6805 & 0.7600 & 0.3070 & 0.97 & -0.70 & 38 & $\begin{array}{c}95.0 \\
\%\end{array}$ \\
\hline $\begin{array}{c}\text { t-stat } \\
\text { (p-value) }\end{array}$ & $\begin{array}{c}0.759 \\
(0.219)\end{array}$ & $\begin{array}{l}-1.771 \\
(0.077)\end{array}$ & & & & & \\
\hline
\end{tabular}

Table 4 shows the results of hypothesis testing for personal anchoring measure data (APi) both for total sample and for male and female respectively. In the second column we find that the mean of personal anchoring measures for male and female respondents are both positive, which is again, indicating the presence of anchoring bias. However, the diferences of those means are not significant, as indicated by the t-statistics and p-values. Similarly, the third column shows that the median of anchoring bias among female and male participants are all positive, and the difference was only significant at $10 \%$ level. Therefore, using $5 \%$ level of significance, we cannot identify the difference between female's anchoring bias and that of male participants, regarding their answers to questions of financial and economic indicators.

\section{Hypothesis 3}

In this part we tried to identify the difference between anchoring bias related to the degree of the questions' difficulty. We hypothesized that anchoring bias in "difficult" questions (which are represented by older topics) is higher than anchoring bias in "easy" questions (which are represented by newer topics). Using similar procedure applied in hypothesis 2, we predicted that mean (and median) of anchoring measure for difficult questions ( $A Q_{n}$, difficult) is greater than the mean (and median) of anchoring measure in easy questions ( $A Q_{n}$, easy). Again, a mean difference t-test (independent sample) was applied in order to identify the difference of means, while the diferences in median were tested by 
using Wilcoxon/Mann-Whitney test. The results of those tests are summarized and presented in Table 5.

Table 5: Difficult Questions vs Easy Questions Anchoring Measures

\begin{tabular}{|c|c|c|c|c|c|c|c|}
\hline \multirow{3}{*}{$\begin{array}{l}\text { Question } \\
\text { Category }\end{array}$} & \multicolumn{7}{|c|}{ Mean of anchoring measure for $n^{\text {th }}$ question $\left(A Q_{n}\right)$} \\
\hline & \multirow{2}{*}{$\begin{array}{l}\text { Mean } \\
0.6503\end{array}$} & \multirow{2}{*}{$\begin{array}{c}\text { Median } \\
0.6849 \\
\end{array}$} & \multirow{2}{*}{$\begin{array}{c}\text { Std. Deviation } \\
0.12914\end{array}$} & \multirow{2}{*}{$\frac{\text { Maximum }}{0.84}$} & \multirow{2}{*}{$\begin{array}{c}\text { Minimum } \\
0.38\end{array}$} & \multicolumn{2}{|c|}{$\begin{array}{l}\text { Number of } \\
\text { Positive (\%) }\end{array}$} \\
\hline & & & & & & 21 & $100 \%$ \\
\hline Difficult (11) & 0.6236 & 0.6043 & 0.12367 & 0.82 & 0.47 & 11 & $100 \%$ \\
\hline Easy (10) & 0.6797 & 0.6977 & 0.13503 & 0.84 & 0.38 & 10 & $100 \%$ \\
\hline $\begin{array}{c}\text { t-stat } \\
\text { (p-value) }\end{array}$ & $0.994(0.1665)$ & $\begin{array}{l}-0.986 \\
(0.162) \\
\end{array}$ & & & & & \\
\hline
\end{tabular}

Table 5 shows anchoring measure $\left(A Q_{n}\right)$ for the entire questions as well as for each category of questions ("difficult" questions and "easy" questions). We observed that the mean of anchoring measures are positive for all types of questions. The results of statistical tests show that neither mean nor median of anchoring bias for difficult questions is significantly higher than mean and median of anchoring bias easier for questions.

\section{Hypothesis 4}

The fourth hypothesis is the difference between anchoring bias among non finance students and that of finance students. Again, using similar procedure with the previous hypothesis, we predicted that the mean (and median) of anchoring measure among non-finance major participants (APi, non-finance) is greater than the mean (and median) of anchoring measure in among finance major participants (APi, finance). Similar to the previous part, a mean difference t-test (independent sample) was applied in order to identify the difference of means, while the diferences in median were tested by using Wilcoxon/Mann-Whitney test. The results of those tests are summarized and presented in Table 6.

Table 6: Finance vs Non-Finance Major Personal Anchoring Measures

\begin{tabular}{|c|c|c|c|c|c|c|c|}
\hline \multirow{2}{*}{ Major } & \multicolumn{7}{|c|}{ Personal Anchoring Measure (APi) } \\
\hline & Mean & Median & $\begin{array}{c}\text { Std. } \\
\text { Deviation }\end{array}$ & Max & Min & $\begin{array}{l}\text { Nur } \\
\text { Pos }\end{array}$ & $\begin{array}{l}\text { er of } \\
\text { e (\%) }\end{array}$ \\
\hline Total (86) & 0.6571 & 0.6850 & 0.2589 & 0.97 & -0.70 & 83 & $96.5 \%$ \\
\hline Non-Finance (74) & 0.6968 & 0.7500 & 0.2036 & 0.97 & -0.11 & 73 & $98.6 \%$ \\
\hline Female (12) & 0.4125 & 0.5800 & 0.4089 & 0.65 & -0.70 & 10 & $83.3 \%$ \\
\hline $\begin{array}{c}\text { t-stat } \\
\text { (p-value) }\end{array}$ & $\begin{array}{l}3.796 \\
(0.00)\end{array}$ & $\begin{array}{l}-3.429 \\
(0.00)\end{array}$ & & & & & \\
\hline
\end{tabular}

Table 6 clearly shows that mean and median of anchoring bias among Non Finance major students (0.6898 and 0.7500$)$ are significantly higher than mean and median of anchoring bias among Finance major student (0.4125 and 0.5800). These figures are consistent with Smith's (2011) conclusion that someone with metric knowledge will be more resistant to anchoring bias than someone with mapping knowledge. Students majoring in finance are assumed to study more specifically about finance (and financial/economic issues) and therefore they are assumed to have more metric knowledge than students in the non-finance major. 


\section{Tassya Andini}

On the other hand, non-finance students are assumed to rely on mapping knowledge of finance, due to their interest to other issues. Therefore the finance major students are more resistant to anchoring bias than the non-finance students.

\section{Conclusion}

After reviewing the results of our analysis, finally we arrive at several conclusions, namely:

1. The presence of anchoring bias can be identified among respondents in answering questions regarding Indonesian financial and economic indicators.

2. There is no significant difference between the degree of female's anchoring bias and male's anchoring bias when answering questions regarding financial and economic indicators in Indonesia.

3. There is no significant difference between the degree of anchoring bias in anwering difficult and easy topics regarding financial and economic indicators in Indonesia.

4. Anchoring bias for student with non finance major is higher than anchoring bias for student with finance major.

\section{REFERENCE}

Asri, Marwan (2003). Ketidak Rasionalan Investor di Pasar Modal (unpublished), Pidato pengukuhan Guru besar UGM.

Asri, Marwan (2013). Keuangan Keperilakuan, BPFE Fakultas Ekonmika dan Bisnis UGM, Yogyakarta, ISBN 979-503-575-4.

Brown, N. R. and R. S. Siegler (1993). Metrics and Mapping: A Framework for Understanding Real-World Quantitative Estimation, Psychological Review, Vol. 100, No. 3.

Cen, L., G. Hilary, and K. C. J. Wei (2010). The Role of Anchoring Bias in the Equity Market: Evidence from Analysts' Earnings Forecasts and Stock Returns. Journal of Financial and Quantitative Analysis (JFQA), Forthcoming. Available at SSRN: http://ssrn.com/abstract=967309.

Cross, S. E. and L. Madson (1997), Models of the Self: Self-Construals and Gender, Psychological Bulletin, 122, 5-137.

Epley, N. \& T. Gilovich (2006), The Anchoring-and-Adjustment Heuristic: Why the Adjustments Are Insufficient, Psychological Science, Vol. 10, No. 4.

Feingold, A. (1994), Gender Differences in Personality: A Meta-Analysis, Psychological Bulletin, 116, 429-456.

Ferrel, O.C., Hirt, Geoffrey A., \& Ferrel, Linda. (2009). Business: A Changing World. New York: McGraw Hill.

Fritz, H. L. and V.S. Helgeson (1998), Distinctions of Unmitigated Communion from Communion: Self-Neglect and Over-Involvement with Others, Journal of Personality and Social Psychology, 75, 121-140.

Gabriel, S. and W.L. Gardner (1999), Are There 'His' and 'Hers' Types of Interdependence? The Implications of Gender Differences in Collective versus Relational Interdependence for Affect, Behavior and Cognition, Journal of Personality and Social Psychology, 77, 642-655.

Gilovich, Thomas., Griffin, Dale., \& Kahneman, Daniel. (2002). Heuristics and Biases: The Psychology of Intuitive Judgment. Cambridge: Cambridge University Press.

Helgeson, V.S. (1994), Relation of Agency and Communion to Well-Being: 
Evidence and Potential Explanations, Psychological Bulletin, 116, 412-428.

Helgeson, V. S. (2003), Unmitigated Communion and Adjustment to Breast

Cancer: Associations and Explanations, Journal of Applied Social Psychology, 33, 1643-1661.

Hyde, J. S. (2005), The Gender Similarities Hypothesis, American Psychologist, $60,581-592$.

Kudryavtsev, A., and G.Cohen. (2010). Anchoring and Pre-Existing Knowledge in Economic and Financial Settings, American Journal of Social and Management Sciences, 1(2), 164-180.

Kudryartsev, A., and G.Cohen. (2011). Behavioral Biases in Economic and Financial Knowledge: Are They the Same for Men and Women?, Advances in Management \& Applied Economics, 1 (1), 15-52.

Nofsinger, John. R. (2001). Investment Madness: How Psychology Affect Your Investment And What To Do About It? New Jersey: Prentice Hall

Smith, A. R. (2011). Exploring The Relationship Between Knowledge and Anchoring Effects: Is the Type of Knowledge Important?, Ph. D. Dissertation, University of lowa, lowa research Online: http://ir.uiowa.edu/etd/1264.

Smith, A. R., P. D. Windschitl, and K. Bruchmann (2013). Knowledge Matters: Anchoring Effect Are Moderated By Knowledge Level. European Journal of Social Psychology. 43, 97-108.

Tversky, A., dan D. Kahneman. (1974). Judgment Under Uncertainty: Heuristics and Biases, Science, New Series, Vol. 185, No. 4157, 1124-1131. Published by: American Association for the Advancement of Science.

Williams, B. S. (2010), Heuristics and Biases in Military Decision Making, Military Review, September-October.

\section{About the Authors}

1. Tassya Andini is a Consumer Loan Product Development Manager at Bank Mandiri, the biggest government owned Bank in Indonesia. She earned her Psychology Degree (S. Psi) in 2007 from University of Indonesia and Master of Business Administration (M.B.A, majoring in Finance) in 2013 from Universitas Gadjah Mada, Jogjakarta, Indonesia. Behavioral Finance, a combination of Psychology and Finance is one of her main interests.

2. Marwan Asri is a Finance Professor at Gadjah Mada University, Jogjakarta, Indonesia. He earned his Master of Business Administration (M.B.A. in International Business Finance) in 1982 from Katholieke Universiteit te Leuven, Belgium, and Doctor of Philosophy (Ph.D in Finance) from University of Kentucky, Lexington, USA in 1997. He is the author of Keuangan Keperilakuan (Behavioral Finance), a text book published by BPFE-Gadjah mada University. 